\title{
Exploring the Relationship between Endurance and Strength Training in Power Sports
}

\author{
Mariana Rohleva \\ Correspondence: Dr. Mariana Rohleva, Senior Lecturer, UACEG, Sofia, Bulgaria. \\ Received: December 22, 2016 \\ Accepted: March 10, 2017 Online Published: March 20, 2017 \\ doi:10.11114/jets.v5i4.2292 \\ URL: https://doi.org/10.11114/jets.v5i4.2292
}

\begin{abstract}
The purpose of this research work is to track down the level of relation between strength and endurance in training exercises of handball athletes. The most successful ratio has been established during work with two groups of 10 players each, all of whom are university students. They were trained, respectively, according to the general training methodology, on the one hand, and a programme, developed by us, on the other.

The object of our research is the effectiveness of the different in volume and intensity training work over the level of the identified physical qualities - strength and endurance. The groups are tested at the beginning and at the end of a two-month experimental period, during which 24 training sessions have been performed with the application of:

1. A control run test - $4 \mathrm{~km}$ distance - at individual intensity of $85 \%$ and a pulse frequency of $145-155 \mathrm{~b} / \mathrm{min}$. The intensity is calculated on the basis of the best result, accomplished by the player. The pulse frequency is measured with a field micro-coordinator Seka, Sportronic-250 and an analytical record, TYP, 2D, Syntron, Seka Software, Version 1.3, England.

2. A strength test consisting of 5 sessions of eight repeats - semi-squats with bar - $40 \%$ of the maximum individual capability for 35 seconds.

It has been established that the combination between workouts for strength and ednurance in a ratio of 2:1 respectively, gives a positive influence on both qualities. A training focused on endurance has a less significant effect on the strength of the athlete, and reversely, strength has a greater effect on endurance. It is recommended that in power sports the relative element of endurance in training not exceed $25-30 \%$, and in sports with endurance as a leading quality - training for strength be in the margin of $20-30 \%$.
\end{abstract}

Keywords: endurance, strength, exercises, training, ratio

\section{Introduction}

For a long time has the topic at hand raised a controversy about the two sporting qualities strength and endurance whether they are in conflict or they complement each other. The possibility to increase the physical performance of athletes using loads of similar nature has been a challenge, as well as the question of how the qualities interact according to the level of improvement. Despite the numerous studies, the issue about whether and to what extent workouts for strength and endurance are involved in the intellectual and mental activity of the athlete is still demanding enlightenment. On the other hand, there is an interesting difference between physical performance, endurance and overall physical performance and what constitutes it.

Firstly, research by Ozolin (1956) defines the terming of "general" performance and endurance as untenable. He believes that in every physical activity and sport there is a typical in itself sporting performance, which should not be identified as "general". Such observations are made by Zatsiorsky and Volkov (1967), Zheliazkov and Dasheva (2011), and others.

It is comparatively accepted (Mateev \& Kisselkova, 1961; Mateev, 1957; Rosenblat, 1975) that the term endurance be defined as the ability of the organism to resist fatigue and negative adverse factors, internal and external alike. Special attention is given to the problem of the interaction between muscle strength and endurance. We found many contradictions in research. Some support the theory that there is a positive relationship between the two qualities (Bachev et al., 2014; Kotz, 1984; Rachev, 1991; Ter Ovanesian, E. \& Ter Ovanesian, I., 1986; Farfel \& Kotz, 1970; Hettinger, 1964), while others are of the opposite opinion - Burelkevich (1982), Kuznetsov (1983), Stefanova (1987), Evans (1951). As it is noted by Krestovnikov (1951), Zatsiorsky and Volkov (1967), and others, differences in opinion occur because of the 
differences in research methodology implemented by the authors. Endurance is suggested to be categorized as "absolute," "relative", "power", "special", "sprinter" and so on (Burelkevich, 1982; Dimitrov, At. \& Dimitrov, D., 2008; Zheliazkov \& Dasheva, 2011; Kuznetsov, 1983; Hettinger, 1964).

The term "physical performance" is perceived as "the ability to perform certain motor tasks within certain limits of external conditions and the level of efficiency in the performance" (Zatsiorsky \& Volkov, 1967; Evans, 1951; Hill, 1927).

Both physical conditions are related to the presence of fatigue, which is the main factor limiting the performance and the effects of endurance. There are two theories about fatigue: humoral and logistical (peripheral), which is maintained by scholars such as Uhtomski (1952), Zatsiorsky and Volkov (1967), on the one hand, and the central nervous-marrow theory, followers of which are Pavlov (1949), Mateev and Kisselkova (1961). Other scholars such as Sechenov, Pavlov and Vedenski (1952) consider that the source of fatigue occurence is not only in muscles but also in the central nervous system and it is, by nature, a biological cortex-held response, and by its physiological mechanism - a reduction of performance, above all, in the cortical cells themselves having the effect of a guarding, protective inhibition.

Other research (Evans, 1951; Mateev, 1957) concludes that the phenomenon of muscle fatigue in the living body is governed by a self-regulatory reflex system, which, with an increase of nerve signals, alone decreases and stops the activity of the muscle long before the energetic potential has been exhausted (Pavlov, 1949; Bikov, 1954).

The combination of training for strength and endurance was the aim of many researchers: Burelkevich (1982), Bachev (2014), Hettinger (1964). Strength training is seen as a means of increasing the level of sporting achievement. By developing this quality, the capabilities of the athlete in power and speed-power sports are improved. Ovanesian (1986) was one of the first to indicate that strength does not interfere with sports with predominant manifestation of endurance. Concurrently with him and later (Bachev, 2014; Dimitrov, At. \& Dimitrov, D., 2008; Kuznetsov, 1983; Stefanova, 1987; Hettinger, 1964), it was found in a number of sports that physical strength has a positively stimulating influence on the other qualities of the athlete, including endurance.

\section{Method}

The study aims at establishing to what extent strength affects endurance and vice versa - endurance vis-a-vis the strength capabilities of an athlete. This is, of course, a general standpoint. In order to achieve more clarification, we have set forth three main objectives that underlie the employed exercises and the sought overall performance results, discussed in the present research project.

\subsection{Objectives}

A. To organize appropriate research through the establishment of two experimental groups working on our proposed methodology;

B. To investigate the impact of one quality over the other and adjust relevant parameters that characterize the level of both qualities;

C. Study on the effectiveness of a different volume training work to develop these qualities.

\subsection{Participants and Organisation}

In university conditions we have built two equivalent training groups of 10 students, regularly engaged in sports that were practiced at the beginning and the end of the study, using two exercises that characterize the level of the appropriate quality:

- 1. Four kilometer run test with individual intensity of $85 \%$ and a heart rate of $145-155$ beats / min.;

- 2. Strength test, consisting of 5 sessions of 8 reps with semi squat bar $-40 \%$ of the maximum capability for 35 seconds.

- Training takes place in the University twice a week as extracurricular activities and once during the regular lesson. Training continued for two months with a total of 24 training sessions for each group. The first experimental group worked twice with an emphasis on strength and endurance for a workout, and the second group with two workouts for endurance and one for strength.

\section{Results}

The results of the first testing showed the solidity of the groups and non-statistical difference in the level of their performance. In the endurance test, differences are 0.13 seconds better in the first group and by 0.9 squats for strength group. 
Table 1. Start and end indicators for control exercises in both experimental groups.

\begin{tabular}{|c|c|c|c|c|c|c|}
\hline \multicolumn{7}{|c|}{ Start and end indicators of the control exercises in both experimental groups } \\
\hline Exercise/first gr. & Stat. Ind. & Start & End & Absolute gr. & Rel. gr. \% & Co-rel. co-eff. R \\
\hline \multirow{5}{*}{$\begin{array}{l}\text { 1. Endur./min. } 4 \mathrm{~km} \\
\text { run steady tempo- } \\
\text { pulse } 145-155 \mathrm{~b} . / \mathrm{min} \text {. }\end{array}$} & $\overline{\mathrm{X}}$ & 20,53 & 18,44 & & $10,18 \%$ & \multirow{10}{*}{0,475} \\
\hline & $\mathrm{S}$ & 1,91 & 1,61 & & & \\
\hline & $s \bar{x}$ & 0,85 & 0,65 & & & \\
\hline & $\mathrm{V}$ & 9,30 & 8,73 & & & \\
\hline & PT & - & - & 0,99712 & & \\
\hline \multirow{5}{*}{$\begin{array}{l}\text { 2. Strength- no. semi } \\
\text { squats for } 35 \mathrm{sec} \text {. }\end{array}$} & $\bar{x}$ & 20,60 & 30,50 & & $48,06 \%$ & \\
\hline & $\mathrm{S}$ & 2,68 & 2,10 & & & \\
\hline & $s \bar{x}$ & 1,19 & 0,94 & & & \\
\hline & $\mathrm{V}$ & 13,00 & 7,04 & & & \\
\hline & PT & - & - & 0,9984 & & \\
\hline
\end{tabular}

\begin{tabular}{|c|c|c|c|c|c|c|}
\hline Exercise/second gr. & Stat. Ind. & Start & End & Absolute gr. & Rel. gr. \% & Co-rel. co-eff. R \\
\hline \multirow{5}{*}{$\begin{array}{l}\text { 1. Endur./min. } 4 \text { km } \\
\text { run steady tempo- } \\
\text { pulse } 145-155 \text { b./min. }\end{array}$} & $\bar{x}$ & 20,40 & 16,28 & & $20,19 \%$ & \multirow{10}{*}{0,862} \\
\hline & $\mathrm{S}$ & 1,80 & 1,58 & & & \\
\hline & $s \bar{x}$ & 0,80 & 0,64 & & & \\
\hline & $\mathrm{V}$ & 8,82 & 9,70 & & & \\
\hline & PT & - & - & 0,9992 & & \\
\hline \multirow{5}{*}{$\begin{array}{l}\text { 2. Strength- no. semi } \\
\text { squats for } 35 \mathrm{sec} \text {. }\end{array}$} & $\bar{x}$ & 19,70 & 22,08 & & $15,73 \%$ & \\
\hline & $\mathrm{S}$ & 3,17 & 3,31 & & & \\
\hline & $s \bar{x}$ & 1,41 & 1,48 & & & \\
\hline & $\mathrm{V}$ & 16,09 & 14,51 & & & \\
\hline & PT & - & - & 0,9074 & & \\
\hline
\end{tabular}

The training sessions, conducted with various orientation table 2 , showed that the volume of specific work for the appropriate quality gives an expected improvement in itself. The first group, which trained for strength as a priority /two classes/ improved results in the strength exercise with 9,9 no. semi-squat in individual weight at $40 \%$, while the test for endurance has improved only with $2.09 \mathrm{sec}$. It should be noted that the indicator for the mean square deviation of the results of their averages indicate that both in the first and in the second group vary in the same range, indicating that the changes are credible and the reason for improvement lies in the accomplished training work. The calculations of the coefficient of variation $/ \mathrm{V} /$ give us an idea how these results reveal individual differences on the average. In the first and second group, we can definitely confirm that the study is informative, as after appropriate training individual differences are found to be very significant. As regards the level of $\mathrm{V}$ in the endurance test, the differences in both groups are minimal, probably because of the small number of participants. The arithmetic average of the increment and indicators of the standard deviation show that significant changes occurred in the groups thanks to training work done. This confirmed the high ratio of the T-criterion which compares averages between baseline and final results in testing. In both tests of the two groups, the rate was first in strength from 3.78 to 1.68 , and for endurance from 2.98 to 4.17 , which corresponds to a confidence of over 0.999 confidence level.

Table 2. Direction of the training work in both experimental groups.

\begin{tabular}{|c|c|c|}
\hline \multicolumn{3}{|c|}{ Focus of the training work in the two experimental groups } \\
\hline Groups & First & Second \\
\hline First workout & $\begin{array}{c}\text { Strength- } 5 \text { cycles } 8 \text { reps } \\
\text { semi-squat } 40 \% \text { bar for } \\
35 \text { sec. }\end{array}$ & $\begin{array}{c}\text { Endurance- } 4 \mathrm{~km} \text { steady run } \\
145-155 \mathrm{~b} . / \text { min. }\end{array}$ \\
\hline Second workout & $\begin{array}{c}\text { Endurance- } 4 \mathrm{~km} \text { steady } \\
\text { run } 145-155 \mathrm{~b} . / \text { min. }\end{array}$ & $\begin{array}{c}\text { Strength- } 5 \text { cycles 8 reps } \\
\text { semi-squat } 40 \% \text { bar for 35 } \\
\text { sec. }\end{array}$ \\
\hline Third workout & $\begin{array}{c}\text { Strength, as in first } \\
\text { workout }\end{array}$ & Endurance, as in first workout \\
\hline
\end{tabular}

As can be seen from Table 2, in the first group the ratio of strength work compared to that of endurance is $66.67 \%$ to $33.33 \%$. The second group has the endurance as a priority to the strength - respectively $66.67 \%$ to $33.33 \%$. During the training sessions this ratio is observed. With increasing of the fitness level, the duration of the running work on endurance grew and so did the volume of the work for strength. In the last (twelfth) week, the four-kilometer run of the first group, which began at 22,30 min. average training time, gradually reached 19,22 minutes. Similar measurements were recorded in the second group, as well. The purposeful work for endurance enhanced the quality and intensity of the training operation; initially the average working time was 22.18 minutes, and at the end $-17,10 \mathrm{~min}$. 
Both absolute and relative indicators of changes in the two capacities show different dynamics. When trainees work prioritarily for strength in the first group, endurance improved by $10.18 \%$ with increasing strength capacity by $48.06 \%$. This gives us grounds to assume that strength training influences endurance by depressing it, as the latter's absolute growth rate is $2.09 \mathrm{~min}$., while the equivalent growth of strength is of $9,92 \mathrm{no}$. reps $/ \mathrm{min}$. Obviously, for practical work such a combination of strength and endurance is acceptable for sports with a priority demand for strength in nature and is not appropriate for those which clearly manifest endurance.

In the second group, where the two qualities are opposed in volume, the increment of the endurance was 20.19 percent against 15.73 percent for strength. These data show that the improvement of endurance is affected reciprocally by the strength. If we compare the two increments - for endurance in the first group and for strength in the second group, we find that strength in the second group is influenced less than the endurance and it has a higher growth rate of $15.73 \%$, while the endurance in the first group, relative to the strength, has improved only by $10.18 \%$. Out of this correlation analysis, we found that there was a close relation between endurance and strength /R-0.862/ and a weaker one between strength and endurance in the first group /R-0.475/.

\section{Discussion and Conclusions}

The relationship between strength and endurance as separate physical qualities, which have great importance in the sporting performance, is a complex one. In addition, results may differ according to the methods that are used in exploring this relationship. Our approach has proved to be useful, as it is simple and has given specific results. It does not have the pretence nor ambition to resolve the question in all complex aspects, but it does, we believe, shed some light that can be used by coaches and sports people alike in planning and managing their fitness work.

Through the use of our testing methodology, at least three specific results have been established, which can be applied in many sports, but essentially they are considered valid for power sports. The results are concluded as follows:

1. Experimentally, it was found that the combination of strength training and endurance in 2:1 ratio has a positive impact on both properties, i.e. there is a certain minimum interdependence.

2. Training for endurance has a lesser impact on strength and a greater one on endurance when the priority is for development of strength.

3. In both groups, increase of the intensity of exercises (reducing the time taken to run the 4 kilometer distance in the second group and increase of the relative weight in the first group) proved decisive for the effectiveness of training and more economical in terms of lost time. Therefore, in practice for power sports, it can be recommended that the proportion of the endurance work should not exceed $25-30 \%$, while for those with a manifestation of endurance, strength training should not be more than $20-25 \%$.

\section{References}

Bachev, V. et al. (2014). Contemporary Methods for Research on Muscular Strength, Sofia: Avantgarde [in Bulgarian]

Bikov, K. M. (1954). Physiology Textbook, Moscow: Physical Culture [in Russian]

Burelkevich, V. (1982). Physical Performance Under Extreme Conditions of Muscle Activity, Moscow: State V. I. Lenin univ. [in Russian]

Dimitrov, A., \& Dimitrov, D. (2008). Physical Preparation of the Alpine Skier, Sofia: RA.Kiwi [in Bulgarian]

Evans, L. C. (1951). Principles of Human Physiology, London, L: J. \& A. Churchill

Farfel, V. S., \& Kotz, E. M. (1970). Human Physiology, Moscow [in Russian]

Hettinger, I. (1964) Isometrisches Muskeltraining, Stuttgart: GRIN Verlag [in German]

Hill, A. V. (1927). Muscular Movement in Man, New York, NY: McGraw - Hill

Kotz, E. M. (1984). Physiology of Muscle Activity, Moscow: Physical Culture [in Russian]

Krestovnikov, A. N. (1951). Essays on the Physiology of Physical Exercises, Sofia: Medicine and Physical Education [in Russian]

Kuznetsov, V. (1983). Modelling of Competitive Activity, Thesis Reports. Moscow: All-Union Conference [in Russian]

Mateev, D. (1957). Muscular and General Fatigue, Sofia: Scientific Session, High Institute for Physical Education Georgi Dimitrov [in Bulgarian]

Mateev, D., \& Kisselkova, E. (1961). Electromyographic and Electro-Encephalomyelitis Graphical Features of Muscle Work and Fatigue, Sofia: Int'l Conf. on the Physiology of Sport [In Bulgarian]

Ozolin, N. G. (1956). Athletics, Moscow: Physical Culture [in Russian] 
Pavlov, I. P. (1949). Investigation of the Higher Nervous Activity, Moscow: Full Compilation of Articles, Vol. 3 [in Russian]

Rachev, K. (1991). Theory and Methods of Physical Education, Sofia: Medicine and Physical Education [in Bulgarian]

Rosenblat, V. (1975). The Problem of Fatigue, Moscow: Medgiz [in Russian]

Sechenov, I. M., Pavlov, I. P., \& Vedenski, N. E. (1952). Physiology of the Nervous System, Moscow: Selected Works of the Academy of Medical Sciences [in Russian]

Stefanova, D. (1987). Adaptation of the Organism Under the Influence of Sports Training, Sofia: Issues on Physical Education, No.10 [in Bulgarian]

Ter Ovanesian, E. J., \& Ter Ovanesian, I. (1986). Pedagogy of Sport (pp. 208-220). Kiev: Zdorov'ya [in Russian]

Uhtomski, A. A. (1952). Excitement, Fatigue, Sedation, Moscow: Medgiz [in Russian]

Zatsiorsky, V. M., \& Volkov, N. (1967). Biochemical Basis of the Athlete's Endurance, Moscow: Journal TPFK, Vol. 4 [in Russian]

Zhelyazkov, T. \& Dasheva, D. (2011). Theory of Sports Training, Sofia: Gera Art [in Bulgarian]

\section{Copyrights}

Copyright for this article is retained by the author(s), with first publication rights granted to the journal.

This is an open-access article distributed under the terms and conditions of the Creative Commons Attribution license which permits unrestricted use, distribution, and reproduction in any medium, provided the original work is properly cited. 